given the right strains and a willingness to alter methods of farming. But they also provide the classic example of how relatively trivial sums of money spent wisely-the budget of IRRI for 1966, apart from money spent on training scientists, was a mere $\$ 1,380,000$ and CIMMY'T's budget was just under $\$ 800,000$ - can change the outlook for hundreds of millions of people. The two foundations know they have the answer to world food shortages, which is why they have agreed to finance two new Centres for

\section{Why Do Students Fail?}

BrItIsII universities have no reason to feel satisfied with the survey just carried out by the University Grants Committee into what is sometimes called student wastage. It is true that the figures showing how many students leave universities without degrees (see page 549) are no worse than before, but it should be a source of sorrow that they are no better. Although the universities have in the last five years been passing through a period in which potential students have been expected to produce solid evidence of their capabilities, there seems to have been no significant improvement in the wastage rates. In international terms, the fact that something over 13 per cent of British students leave university without degrees may be taken by some as a token of success; wastage rates elsewhere in the world are certainly much higher, but this probably reflects differences of philosophy.

Two things are striking about the figures. For one thing, they have been remarkably constant over the past ten or fifteen years, surviving all the changes which have taken place in British universities during that time. Of the students who entered universities in 1955,14 per cent emerged without a degree, almost the same proportion who failed to graduate in 1966 . It is also disturbing that science and technology students are particularly likely to leave university without degrees. The figure for science is only marginally above the average, but in technology no less than 21.8 per cent of the students failed for one reason or another, a proportion which has been maintained within a percentage point or two ever since 1952 .

It is, of course, quite possible that the constancy of the wastage rates provides a elue towards understanding why they exist at all. The report of the Robbins Committee in 1963 was not the first document to point out that "in some faculties there is an approximate percentage of students whom it has become customary to fail". In colleges of technology, it has apparently been customary to fail a rather higher proportion of students than in universities, so some improvement in the figures can be expected now that the colleges have become universities. The higher entrance qualifications now demanded may also have the effect of reducing the wastage in technology.

The UGC has shown uncharacteristic independence of mind in publishing for the first time figures which enable direct comparison to be made between the universities. This splendid innovation, shirked by
Tropical Agriculture. No doubt it would be expecting the impossible to hope that the yield of every crop can be increased quite as quickly and by so large a margin, but so little is known about most tropical crops that significant improvements in yield are bound to follow a concerted research programme. And that inevitably raises the question of why these improvements have to depend on Ford and Rockefeller philanthropy. What are national governments and the international agencies waiting for?

the Robbins Committee which published the figures but made the universities impossible to identify, at last makes it possible to decide whether different teaching methods affect the wastage rates. One can ask, for instance, why 19 per cent of the mathematicians at Birmingham University failed, while Leeds, with a school of much the same size, got all but 3.9 per cent of them through. Why are arts students at Scottish universities three times more likely to fail for academic reasons than their counterparts at English universities? No doubt many of these differences are caused by the difficulties of defining the reasons for failure, but some of the discrepancies are far too large to be explained away like this.

Apart from this, the figures show how small a part the final examinations play in determining failure. Whether they realize it or not, British universities are practising a form of continuous assessment which makes it certain that the vast majority of those who sit their final examinations pass them. Only 1.4 per cent of those who sat their final examinations failed; the most important examinations, it seems, come at the end of the first year, when about half the total wastage occurs. This is not, perhaps, a very surprising conclusion-some departments are known to use the first year examinations as a means of weeding out a proportion of the entrants. But is it logical that the most important judgment of a student's competence should come at a time when he has scarcely had time to find his feet, or to take advantage of university teaching methods? It may be more economical, if a given number of students are to fail, to fail them at the end of the first year rather than at the end of the third, but it is not a very creditable way to behave. For one thing, it reflects a lack of confidence in university teaching. For another, the examinations at the end of the first year have become much more important than final examinations.

In this sense, it would be much more satisfactory if a greater part of the failure occurred at the final hurdle, if only because it would make it easier for those who fail to try again. But it would be better still if the total wastage could be quite rapidly reduced. The Robbins report declared that "it should be an essential part of the responsibility of any university department . . to investigate this problem carefully". To judge from the results of the UGC enquiry, very little progress has been made. 